\title{
Control and Modelling of Capillary Flow of Epoxy Resin in Aligned Carbon Nanotube Forests
}

\author{
James D Beard ${ }^{*} \dagger$, Davood Rouholamin $\dagger$, Benjamin L Farmer $\neq$, Ken E Evans $\dagger$, Oana R Ghita
}

\author{
AUTHOR ADDRESS \\ $\dagger$ Exeter Advanced Technologies, College of Engineering, Mathematics and Physical Sciences, \\ Harrison Building, University of Exeter, Exeter, EX4 4QF UK
}

$\ddagger$ Airbus Corp. Ltd. (Airbus Group), Building 20A1 (Ground Floor), Filton 20, Golf Course Lane, Filton BS54 7QW UK

KEYWORDS Carbon nanotubes, capillary flow, epoxy, nanocomposites, composites, energy dispersive $\mathrm{x}$-ray spectroscopy, additive layer manufacturing,

ABSTRACT This paper examines the mechanism of infiltration by capillary flow of liquid epoxy resin into vertically-aligned carbon nanotube forests fabricated by chemical vapour deposition. The resin viscosity during cure was characterized by rheometry. Carbon nanotube forests were brought into contact with liquid resin at a range of times during the cure process, therefore at a range of resin viscosities. The extent of penetration of the resin into the nanotube forest was measured using electron microscopy, x-ray micro-computed tomography and energydispersive $x$-ray spectroscopy, the latter relying on a chromium-complex dye additive in the resin which acts as a marker for the presence of resin. The experimental results were compared to a 
simulation based on the Implicit Lucas-Washburn equation for capillary flow. It was found that prior to the resin gel point, the resin penetrates through the full height of the nanotube forest. Close to the gel point, the resin ceases to flow into the forest, leaving unwetted regions of nanotubes. Understanding the relationship between resin flow in nanotube structures and the resin viscosity and cure rates has important application in the fabrication of nanocomposite materials. In our case, this "partial wetting" effect is a key requirement for a previously proposed method for the fabrication of carbon nanotube composites by additive layer manufacture (ALM) which would provide strong interlayer reinforcement combined with the versatility of ALM.

\section{TEXT}

\section{INTRODUCTION}

First recognized in 1991, , carbon nanotubes (CNTs) are light, nanoscale carbon filaments with unusual electronic properties as well as extremely high tensile strength and aspect ratio. As a result of these properties, there is great interest in their use as reinforcement fibres in composite materials, as well as components in nanoscale transistors, atomic force microscope probe tips, sensing devices, supercapacitors, thermoelectric generators and a wide range of other applications. ii ,ii iv ,,

Alignment of reinforcement fibres is highly desirable in composite materials to enhance the reinforcement effectiveness of the fibres, particularly against forces exerted along the fibre axis. Vertically aligned carbon nanotube (VA-CNT) forests can be fabricated by chemical vapour deposition (CVD) based on the decomposition of hydrocarbon gases (e.g. ethylene, methane) at 
high temperatures. These forests form as arrays of parallel filaments which "grow" perpendicular to a growth substrate coated with a catalyst (typically iron or nickel) which promotes their growth. ${ }^{\text {vi }}$,ii Previous studies have shown that VA-CNT arrays can be grown to heights of several millimetres. viii ix Aligned carbon nanotubes have been shown to act as effective reinforcement of a variety of polymer matrices,, xi xii xiii and also the encapsulation of nanotubes in polymer is commonly used to stabilize the nanotube structure for the fabrication of nanotube-based electronic devices. ${ }^{\text {xiv }}$

The strong alignment demonstrated in forests fabricated by CVD has been shown to reinforce epoxy resins and other matrix polymers, both parallel and perpendicular to the nanotube axis x,xi,xiixiii (perpendicular reinforcement occurring due to inherent waviness of the nanotubes). ${ }^{\text {iv }}$ These resins must successfully penetrate the nanoscale gaps between nanotubes in as-grown forests to bind to the nanotubes and form an effective composite. This penetration is thought to occur by a capillary flow process with the liquid resin drawn into the small intertube gaps by capillary action.

Nanotubes therefore are exciting candidates as reinforcements in nanocomposite materials. However, there remain challenges in scaling up of nanocomposite fabrication methods and integration of nanotube composites with modern manufacturing methods. In recent years, a revolution in manufacturing methods has occurred, driven by Additive Manufacturing (AM) methods, which allow great versatility in design and form. Integrating nanocomposite production with AM techniques would allow the production of highly complex structures with enhanced mechanical strength and other properties. 
A proposed method for ALM production of a composite structure with nanotubes providing interlayer reinforcement is illustrated in figure $1{ }^{\mathrm{xv}}$ In this concept, nanotube forests are inserted into a liquid polymer layer which is cured such that the polymer penetrates the forests by capillary flow but does not fully wet the nanotube forest. This leaves a region of the forest which can be embedded in a second polymer layer such that the nanotubes bridge the layer boundaries, and thus provide interlayer reinforcement; effectively creating nanotube-resin composite "pins" which bind the resin layers together.

A key element of this process is the control of the resin wetting into the carbon nanotube forests such that the resin penetrates only a limited distance into the forest before the capillary flow ceases. Previous studies in this area have shown that liquid epoxy resins wet rapidly into CNT forests, fully wetting the forest prior to curing and preventing the achievement of "partial wetting". ${ }^{\text {vi }}$ This "partial wetting" process is discussed in this paper and shown to be attainable by careful control of the resin viscosity during curing and timing of the initial contact between the nanotubes and liquid resin. While there have been previous studies into the formation of nanoscale composite structures by infiltration of resin into VA-CNT forests, ${ }^{\text {xvii }}$ this is the first study of the rate of penetration of resin into these structures.

Rheology measurements were carried out to determine viscosity profiles during cure for the resin and combined with a numerical model based on the Implicit Lucas-Washburn model of capillary flow to provide a simulated prediction of the extent of resin flow into the nanotube forests. Further experiments were carried out on VA-CNT forests fabricated by CVD, which were brought into contact with liquid resin during cure and the penetration of the resin into the CNT forest measured after curing. Measurement was carried out by scanning electron microscopy 
(SEM), energy dispersive x-ray spectroscopy (EDS), x-ray micro computed tomography (CT) and optical microscopy to provide experimental verification of the wetting model.

\section{EXPERIMENTAL METHODS}

Carbon nanotubes were localized on silicon substrates using standard photolithography/electron beam lithography (EBL) and CVD techniques. For photolithography, a layer of S1813 photoresist was deposited on clean silicon wafers with $100 \mathrm{~nm} \mathrm{SiO}$ layer (IDB Tech) by spin coating (4000 rpm for 60 seconds), and baked in air for 60 seconds at $120{ }^{\circ} \mathrm{C}$. The resist layer was patterned using a laser writer system (Durham Magneto Optics) and the pattern developed using MF319 developer and rinsed in deionized water. For EBL, a layer of PMMA was deposited onto the $\mathrm{Si} / \mathrm{SiO}_{2}$, baked 10 minutes at $180{ }^{\circ} \mathrm{C}$, patterned using an $\mathrm{SEM}$ system (NanoBeam NB4 Electron Beam Lithography System) and developed using a 15:5:1 IPA:MIBK:EMK mixture and rinsed in IPA.

Deposition of $\mathrm{Al}_{2} \mathrm{O}_{3} / \mathrm{Fe}$ catalyst films [25-40 nm/1-3 nm respectively] was carried out by electron beam evaporation. Following lift-off of the resist in acetone, VA-CNT growth was carried out using a SabreTube desktop thermal processing system with silicon substrate platform heater and external preheater tube, as described in more detail elsewhere ${ }^{\text {xiii }}$, ${ }^{x x}$ using a substrate temperature of $\sim 800{ }^{\circ} \mathrm{C}$ and preheater temperature of $975-990{ }^{\circ} \mathrm{C}$. Helium was used as an inert buffer gas to flush oxygen from the CVD system, and combined with hydrogen to create a reducing atmosphere $\left(120 / 310 \mathrm{sccm} \quad \mathrm{He} / \mathrm{H}_{2} \quad \mathrm{mix}\right)$. The catalyst was annealed in the helium/hydrogen atmosphere for 2 minutes at the growth temperature before introduction of 200 sccm ethylene gas to provide a carbon source for carbon nanotube growth. Nanotube growth occurs to a length of $0.4-0.7 \mathrm{~mm}$ over a period of 1-10 minutes. 
LY3505 epoxy resin was combined with XB3403 hardener (both from Huntsman) in a 100:35 ratio by weight according to the manufacturers' instructions. In order to allow identification of the resin by EDS spectroscopy during SEM, the resin was combined with $21.8 \%$ by weight Solvent Red 8 dye (RialCo). In practice the dye concentration may be lower due to precipitation/agglomeration of the dye. This is a chromium-complex organic solvent dye $\left(\mathrm{C}_{32} \mathrm{H}_{26} \mathrm{CrN}_{10} \mathrm{O}_{8}\right)$. This concentration of dye was selected so that the concentration of $\mathrm{Cr}$ by weight would be $\sim 1.6 \%$, exceeding the detection threshold of Cr by EDS (approximately 1000 ppm by weight) by approximately an order of magnitude.

Viscometry measurement was carried out using an AR2000 rotational rheometer (TA Instruments), with the sample placed between $40 \mathrm{~mm}$ diameter parallel aluminium plates (manufactured in-house) and oscillated at a rate of $1 \mathrm{~Hz}$ to a maximum strain of $2 \%$.

Patterned CNT forests on silicon substrates were attached to glass cover slips for ease of handling, and mounted on a purpose-built dipping rig consisting of an inverted vacuum chuck with a manual XYZ micrometric screw positioning system over a temperature-controlled resin bath. The resin/hardener/dye mix was heated to $110^{\circ} \mathrm{C}$ from room temperature over a period of $\sim 3$ minutes then held at $110{ }^{\circ} \mathrm{C}$, approximating processing in the rheometer. The carbon nanotube forests were lowered into contact with the resin surface at specific resin curing times, starting from the initiation of the resin heating. The nanotubes and resin were left in contact until the resin hardened (15 minutes from the initiation of heating) and then removed from the dipping rig and transferred to an oven at $110{ }^{\circ} \mathrm{C}$ for 75 minutes in air to ensure full curing of the resin.

Samples were cleaved for SEM imaging in cross-section. SEM imaging and EDS measurement were carried out using a Hitachi S3200N SEM-EDS system, using a backscatter detector due to 
the insulating nature of the resin. EDS measurement was carried out using $20 \mathrm{kV}$ accelerating voltage, with data acquired over an 80s period. Test measurements were also carried out on 4 small blocks of fully cured dyed resin (denoted sample A/B/C/D in this paper) containing $21.8 \%$ SR8 to confirm detection of Cr. Samples for SEM/EDS were imaged and measured without any additional conductive coating to avoid affecting the EDS data.

In this study, the volume occupied by the resin in the structure of VA-CNT was measured using micro computed tomography (micro-CT). The VA-CNT samples were scanned using X-Tek Benchtop CT $160 \mathrm{Xi}$ (X-Tek Systems Ltd/Nikon Metrology UK Ltd, England) with the following scanning conditions: current of $100 \mu \mathrm{A}$, voltage of $65 \mathrm{kV}$, pixel size of $3 \mu \mathrm{m}$ and $360^{\circ}$ rotation. The effect of the flow initiation time on the volume occupied by the resin was then investigated and compared using VGStudio MAX software.

A time-stepped model based on the Implicit Lucas Washburn equation was used here to provide theoretical prediction of the resin rise. The Implicit Lucas-Washburn equation is

$$
t(h)=-\frac{8 \mu(t)}{\rho g R^{2}} h-\frac{16 \mu(t) \gamma^{2}}{\rho^{2} g^{2} R^{3}} \ln \left(1-\frac{\rho g R}{2 \gamma \cos (\theta)} h\right)
$$

This provides the capillary rise $h$ at time $t$ within a cylindrical capillary of radius $R$, for a liquid of viscosity at time $t \mu(t)$, surface tension $\gamma$, contact angle with the nanotubes $\vartheta$, and density $\rho$. Values of $\rho=1.16 \mathrm{~g} / \mathrm{cm}^{3}, g=9.81 \mathrm{~m} / \mathrm{s}^{2}, \theta=30^{\circ}$ and $\gamma=0.0341 \mathrm{~N} / \mathrm{m}$ were used based on the work of Allen $^{\mathrm{xvi}}$ using the same resin.

The model was implemented in MATLAB R2013b. $\mu(t)$ was approximated by fitting the equation 


$$
\mu(t)=a e^{b t}
$$

to the viscometry profiles (complex viscosity vs. time) measured for the dyed resin. The coefficients $\mathrm{a}=10^{-5} \mathrm{~Pa} . \mathrm{s}$ and $\mathrm{b}=0.0679 \mathrm{~s}^{-1}$ were used in this simulation.

\section{RESULTS}

Viscosity profiles for both the dyed and undyed resin are shown in figure $3 \mathrm{a}$, and showed a transition from the room temperature viscosity to a much lower viscosity during the initial resin heating, followed by an exponential rise in viscosity as the resin gel point was passed due to the curing of the resin. The gel point of the undyed resin occurred at $\sim 7.8$ minutes after heating. However, in the presence of $\sim 20 \%$ Solvent Red 8 , the resin viscosity was increased and the gel time significantly decreased to $\sim 3.7$ minutes, as shown in figure $3 \mathrm{~b}$. This suggests that the presence of the dye acts both to increase the room temperature viscosity and also accelerates the curing process of the resin e.g. by acting as a catalyst.

The presence of resin was evident from variation in contrast in the SEM images. For resin curing times less than $\sim 3.25$ minutes, the resin was observed to penetrate through the full thickness of the forest $(\sim 0.4-0.7 \mathrm{~mm})$. In addition, numerous cavities devoid of resin or CNTs formed within the forest structure. During this time, according to the viscometry measurements, the resin has a relatively low viscosity due to its initial heating, allowing more rapid penetration into the internanotube spaces. This was also observed in some samples over the range of 3.25-3.5 minutes.

In samples inserted at cure times close to the resin gel time, areas of the nanotube forest devoid of resin were observed, indicating partial wetting. This was principally observed in those placed 
in contact with resin at time equal to or greater than 3.5 minutes; however some unwetted areas are visible in those with resin curing times in the range of 3.25-3.5 minutes. This slower wetting can be attributed to the rapid increase in resin viscosity due to cross-linking of the resin as it approaches its gel point. An example of a partially wetted forest is shown in figure $4 \mathrm{a}$ and $\mathrm{b}$.

In these partially wetted samples, two "wetting modes" were observed; wetting into the base forming a continuous boundary region at the base of the nanotube forest (described in this paper as wetting mode A) and also areas where the resin has penetrated further into the forest, forming pillars (described in this paper as wetting mode B). Examples of pillar-like structures are shown in figure 4a. Similar pillar structures have been observed for nanotube forests wetted with low viscosity epoxy resins at room temperature. ${ }^{\mathrm{xvi}}$ At cure times greater than $\sim 3.5$ minutes, fewer pillar-like structures are observed and mode A dominates. Examples of the resin structures formed by these two modes can be seen in figure 4a-d.

After the gel point, the resin does not appear to penetrate the nanotube forest since it is unable to flow post-gelation, and the VA-CNTs are observed to be stuck to the resin only at the nanotube ends (an example of this is shown in figure $4 \mathrm{e}$ and $4 \mathrm{f}$ ). This is likely due to the resin retaining some adhesive properties even after the gel point.

A third wetting mode (mode $\mathrm{C}$ ) was proposed to explain the formation of resin -free regions between discrete pillars. It is possible that the creation of wider channels into the nanotube forest results in a densification of the VA-CNTs around the channel, decreasing the rate at which the resin is able to penetrate and preventing infiltration of resin close to the pillar, resulting in exclusion of resin from this region. Wetting modes $\mathrm{A}-\mathrm{C}$ are illustrated in figure $4 \mathrm{~g}$. 
The simulation in MATLAB was performed for a range of pore radii $(50,150,500$ and 1000 $\mathrm{nm})$. The simulation outputs a plot of the calculated rise $h$ at time $t$ based on the resin viscosity at $t$. Examples of output curves for a range of pore sizes and cure times are shown in figure 5a.

Depth of penetration into the nanotube forests of the resin was measured from the SEM images using ImageJ software. The results of these measurements are shown in figure 5b. The penetration distance showed a sharp decrease after insertion times of $\sim 3.5$ minutes, with some forests showing no resin penetration at all after this time. In particular, after the measured gel time of $\sim 3.7$ minutes, the resin no longer penetrates the forest, due to cross-linking of the resin preventing further capillary flow.

Further measurements were taken from these images to compare the height of pillars to that of the base boundary region. In the fully-wetted samples, there is no discernable difference between the two modes. However, in other samples it was possible to measure the continuous boundary region and the heights of pillars separately, based on the SEM images. These measurements are shown in figure $5 \mathrm{c}-\mathrm{d}$.

Figure 5e compares the results of the simulated capillary rises for a range of capillary radii to the measured heights of the "boundary region" (wetting mode A). The measured heights are close to those predicted by the simulation over a range of pore radii from $50-1000 \mathrm{~nm}$, but there is significant variation, suggesting that a single pore radius is insufficient to fully characterize the system of resin-nanotube interactions.

X-ray micro-computed tomography (micro-CT) imaging was used to examine the internal structure of wetted forests. Since they occupy only 1-2 \% of total volume of a VA-CNT forest, 
unwetted regions of the CNT forest are not visible on CT scan due to their low density. However, areas of nanotube composite and neat resin are visible using micro-CT imaging.

The volume of the forest occupied by resin can be calculated using appropriate analysis software. The results of this are shown in figure 6. In correlation with the SEM images, it was noted that for shorter flow initiation times the forest becomes almost fully wetted, with a much greater volume occupied by resin. For shorter infiltration times, larger areas devoid of resin are visible, with resin wetting into the forest base (mode A) and rising up through it as pillar-like structures (mode B).

EDS measurements carried out on blocks of resin without carbon nanotubes are shown in Figure 7a and Table 1. The measured percentage of chromium showed significant variation from the amount added to the resin $(\sim 1.6 \%$ by weight $)$, measured at $0.44-0.69 \%$ by weight. This suggests incomplete dissolution of the dye. However, these measurements verified that the chromium dye is detectable by EDS spectroscopy and so can be used as a marker for the presence or absence of resin in the VA-CNT forests.

EDS spectroscopy measurements showed a drop in Cr content by weight across the boundary region between carbon nanotubes and polymer for the partially-wetted forests, significantly larger than the variation in percentage of chromium measured for the resin samples in Table 1 , suggesting the absence of resin in the nanotube forests above this boundary and indicating that the nanotubes above this boundary are unwetted. EDS was used to identify unwetted regions of the nanotube forest by lower $\mathrm{Cr}$ content. 
Percentages of chromium detectable by EDS are shown in figure $7 \mathrm{~b}$ and $7 \mathrm{c}$. The detectable fraction of $\mathrm{Cr}$ decreases further into the VA-CNT forest, particularly in those forests placed in contact with resin after $\sim 3.5$ minutes of heating as the resin approaches its gel point.

\section{DISCUSSION}

As shown in figure 5, the calculated capillary rise from the MATLAB simulation suggested that the penetration of resin into the nanotube forests would be less than that observed for forests with a cure time prior to 3.5 minutes, whereas the experimental results showed the resin penetrating completely through the forest thickness. However, close to 3.5 minutes the simulated rise is similar to that observed in many forests, particularly for an assumed pore radius of $50 \mathrm{~nm}$. This radius of $50 \mathrm{~nm}$ is realistic for intertube separation of nanotube forests grown by CVD, where the nanotubes are separated by a few tens of nanometers.

Before the cut-off at $\sim 3.5$ minutes heating time, resin penetration through the forest is much larger than that predicted by the simulation. In addition, SEM imaging of these samples showed that there are numerous "cavities" within the forests without either nanotubes or resin. Assuming the nanotube forest to be relatively homogenous before the introduction of resin, this suggests that the forest structure is distorted by the infiltration of resin. Distortion of the shape of nanotube forests has been previously observed to occur due to surface tension forces acting on the nanotubes as the resin rises through the forest structure, which tends to cause bundles of nanotubes to contract, and cavities to appear in larger forests. This effect has been termed "capillary forming" ${ }^{x i}$ In addition, trapped air within the forest may also lead to the formation of bubbles in the resin-nanotube composite structure. These two effects (bubble formation and capillary forming) likely lead to the opening of wider channels into the nanotube forest, resulting 
in accelerated capillary flow. This causes the formation of pillar-like structures along these channels, resulting in the formation of pillar-like structures in the resulting wetted forest (wetting mode B) at lower resin viscosities, leading to the deeper penetration of resin observed for forests introduced to the resin at shorter heating times. The eventual pillar height might be determined by narrowing of the channel as it penetrates into the forest, decreasing the effective capillary radius and eventually slowing the penetration of resin. At higher viscosities, the "boundary region" forms at the base of the forest, consisting of a band of nanotubes wetted to an even height (mode A). This height corresponds closely to that predicted by the Lucas-Washburn model for smaller capillary radii, suggesting that there is less displacement of the nanotubes for higher viscosities and the resin does not open wider channels into the nanotube forest, and so penetrates more slowly.

\section{CONCLUSIONS}

This paper examines penetration by capillary flow into vertically aligned carbon nanotube forests. Viscosity profiles measured during resin curing were measured on epoxy resin and on resin combined with a Cr-based dye (Solvent Red 8), demonstrating increased viscosity and decreased cure time in the presence of the dye.

Infiltration of resin into carbon nanotube forests was investigated by placing carbon nanotube forests grown by CVD in contact with resin over a range of cure times. The penetration of resin into the forests was measured using SEM imaging, x-ray micro-CT scanning, and EDS spectroscopy, the latter being able to detect the presence of resin-filled regions of the sample by the presence of the chromium-based dye. 
For shorter cure times, the resin strongly wets the nanotube forest, often causing complete wetting of the VA-CNTs. As the cure time approaches the gel time, the increased viscosity of the resin causes it to penetrate only a short way into the nanotube forest before the gelling of the resin causes the capillary flow to cease, creating a "partially wetted" forest. This demonstrates that the viscosity cure profile can be used to determine a "window" of opportunity for incomplete wetting of the nanotube forest.

Two modes of wetting were identified; the formation of a boundary region of wetted nanotubes of uniform height at the forest base (here termed mode A) and the formation of pillar-like structures penetrating further into the VA-CNT forest (mode B). Mode A is likely due to the infiltration of the polymer by capillary flow into the inter-nanotube gaps, and the penetration depth of resin into the forest in this mode approximates that predicted by the Implicit LucasWashburn model implemented in this experiment.

It is hypothesized here that mode B is caused by displacement of the VA-CNTs by surface tension forces in the liquid polymer, creating wider channels into the VA-CNT forest which allow more rapid capillary flow into these channels. The resin then cures within these channels (and will also infiltrate a short distance into the surrounding VA-CNTs), forming a pillar structure. This more rapid flow also causes the complete wetting of the forest observed at lower resin viscosities, to greater penetration depths than predicted by the Implicit Lucas-Washburn model.

These results are of significance in the development of carbon nanotube-reinforced nanocomposites based on vertically aligned nanotube forests, and the development of other polymer-embedded nanotube devices such as thermoelectric generators and transistor junctions. 
In particular, the demonstrated "partial wetting" is vital for the layer-by-layer fabrication of a continuously reinforced carbon nanotube-polymer structure, as described in the introduction to this paper. The proposed method to incorporate VA-CNT composite interlayer reinforcements into structures fabricated by ALM would open new applications of ALM, combining the widely demonstrated reinforcement effectiveness of CNT composites ${ }^{\text {xi,xi,xiii }}$ with the versatility of design made available by ALM.

\section{FIGURES}
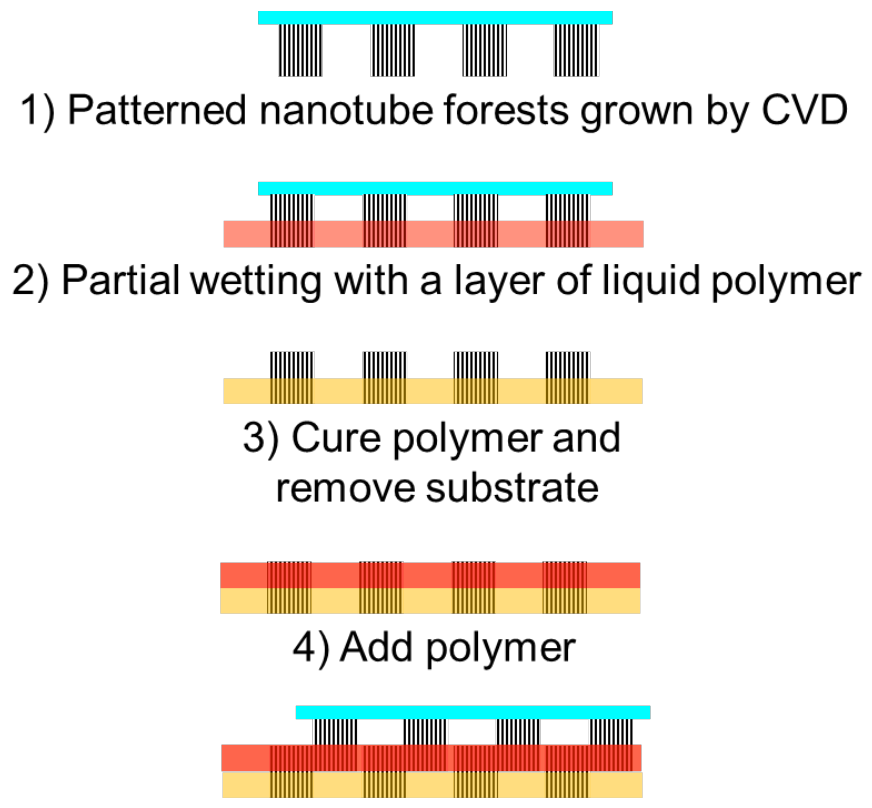

5) Interleave second layer

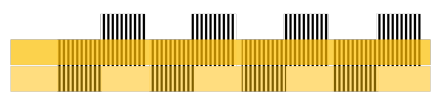

6) Second layer fabrication

Figure 1. Proposed method of manufacture of a continuously reinforced nanocomposite with interleaved carbon nanotube forests by additive layer manufacture (ALM). 


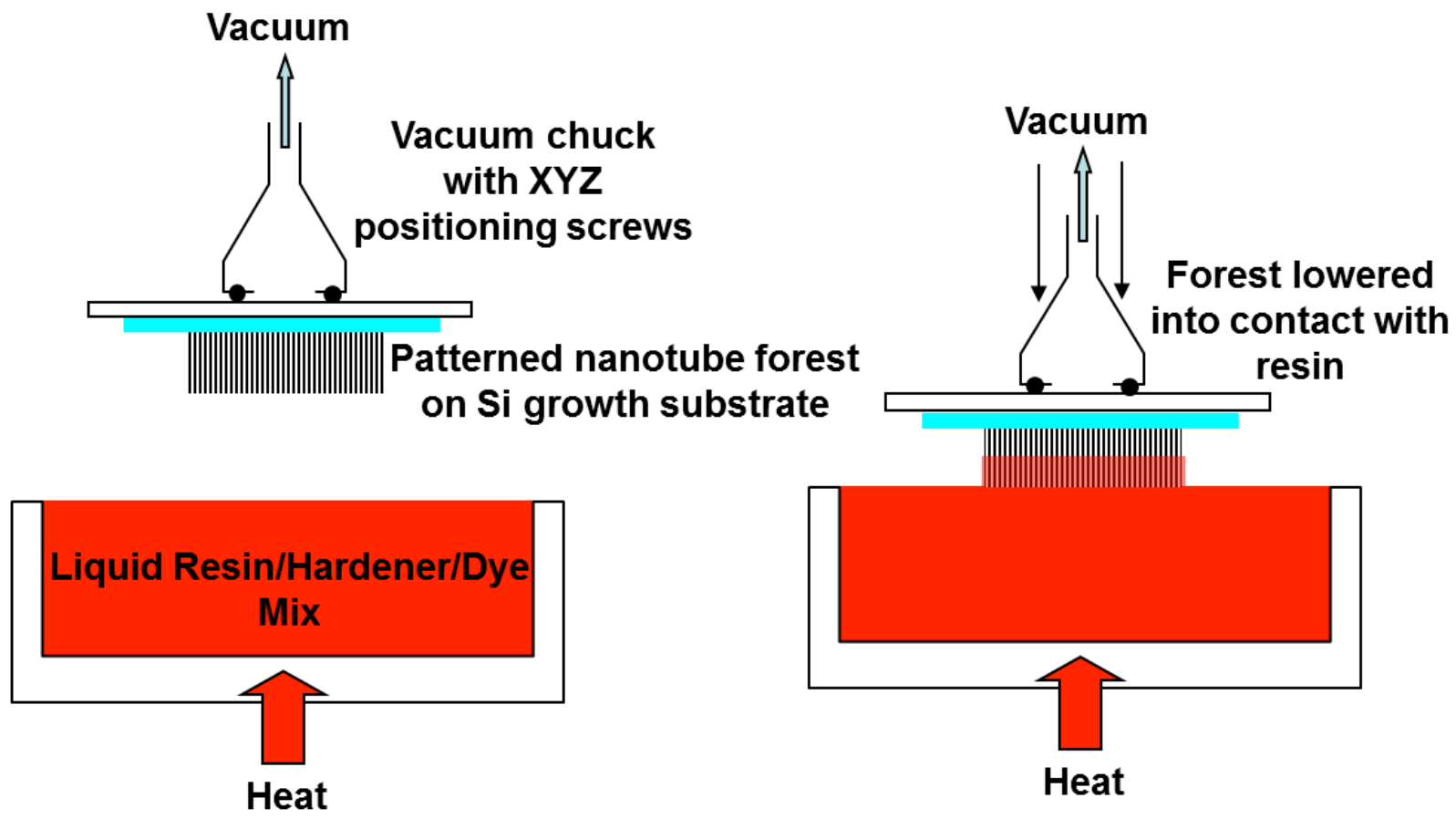

Fig 2. Schematic representation of dipping experiment setup.

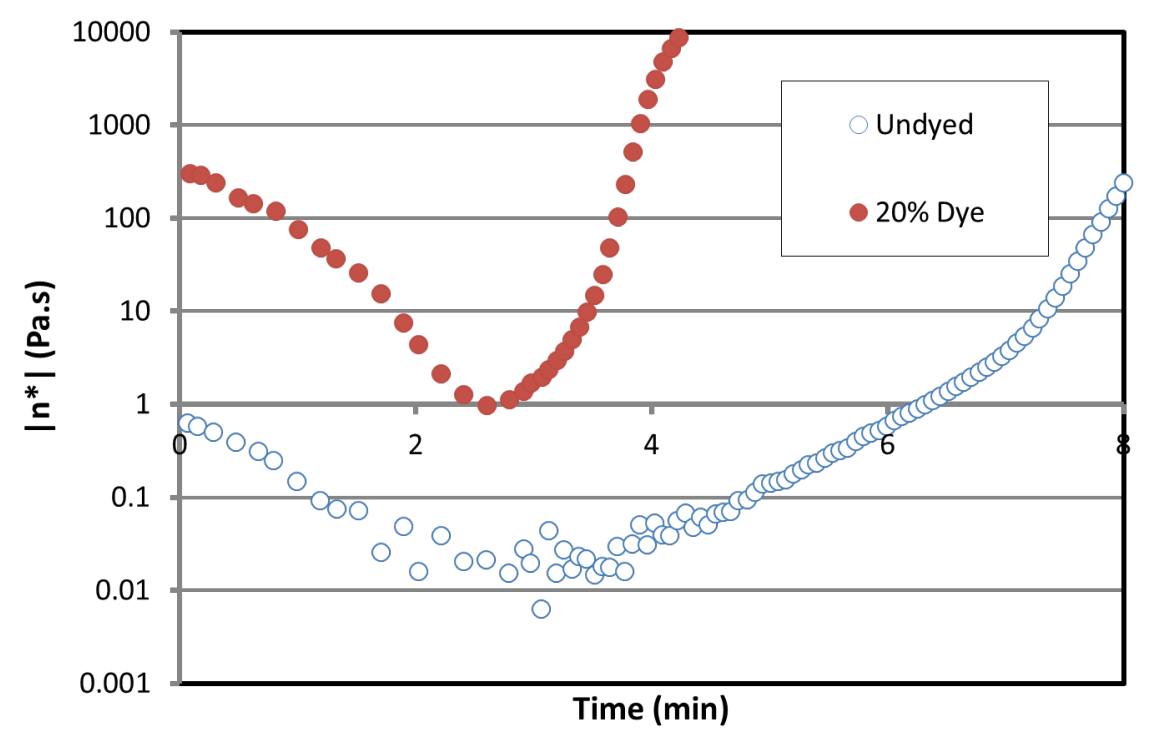




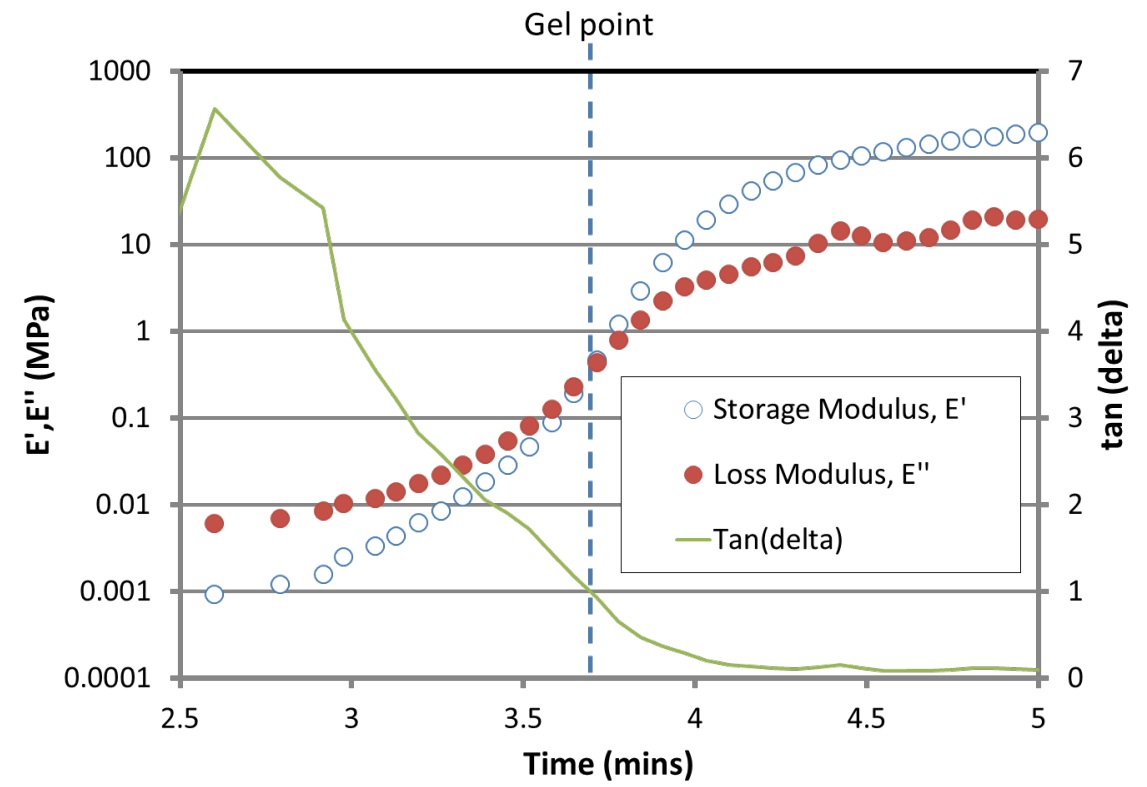

b)

Figure 3. a) Viscosity profiles of dyed and undyed resin during cure. b) Storage and loss moduli of the dyed resin measured by rheology, showing the gel point occurring $~ 3.7$ minutes after the start of heating.

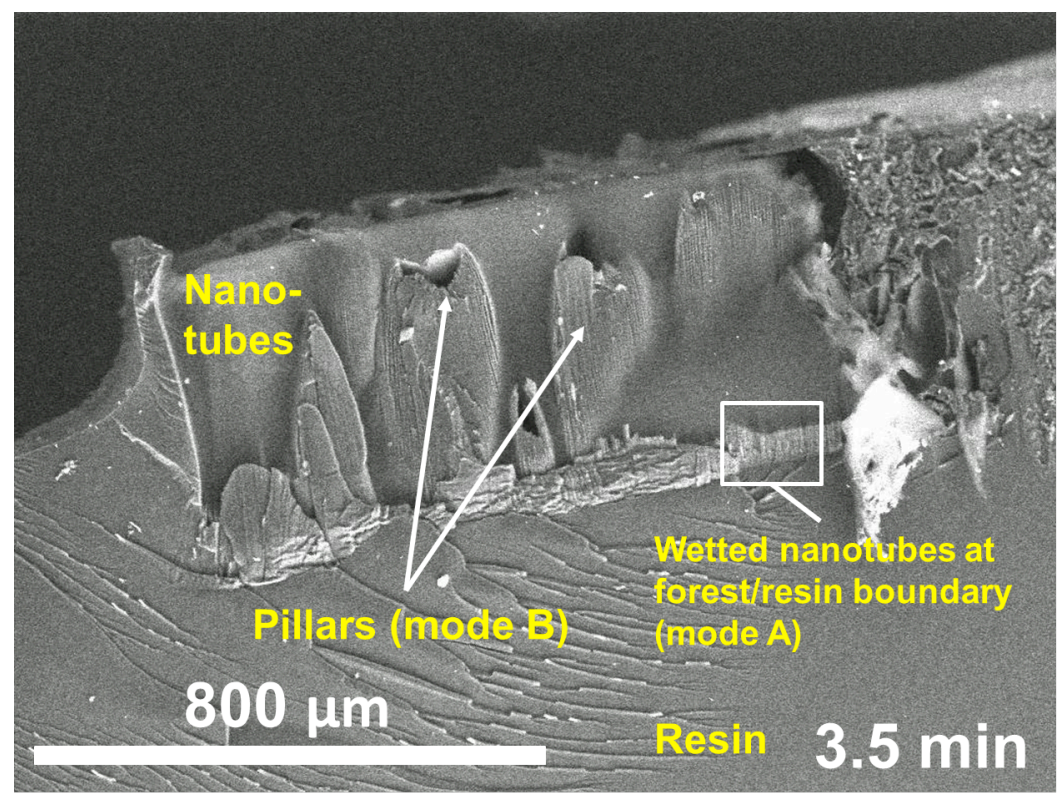

a) 

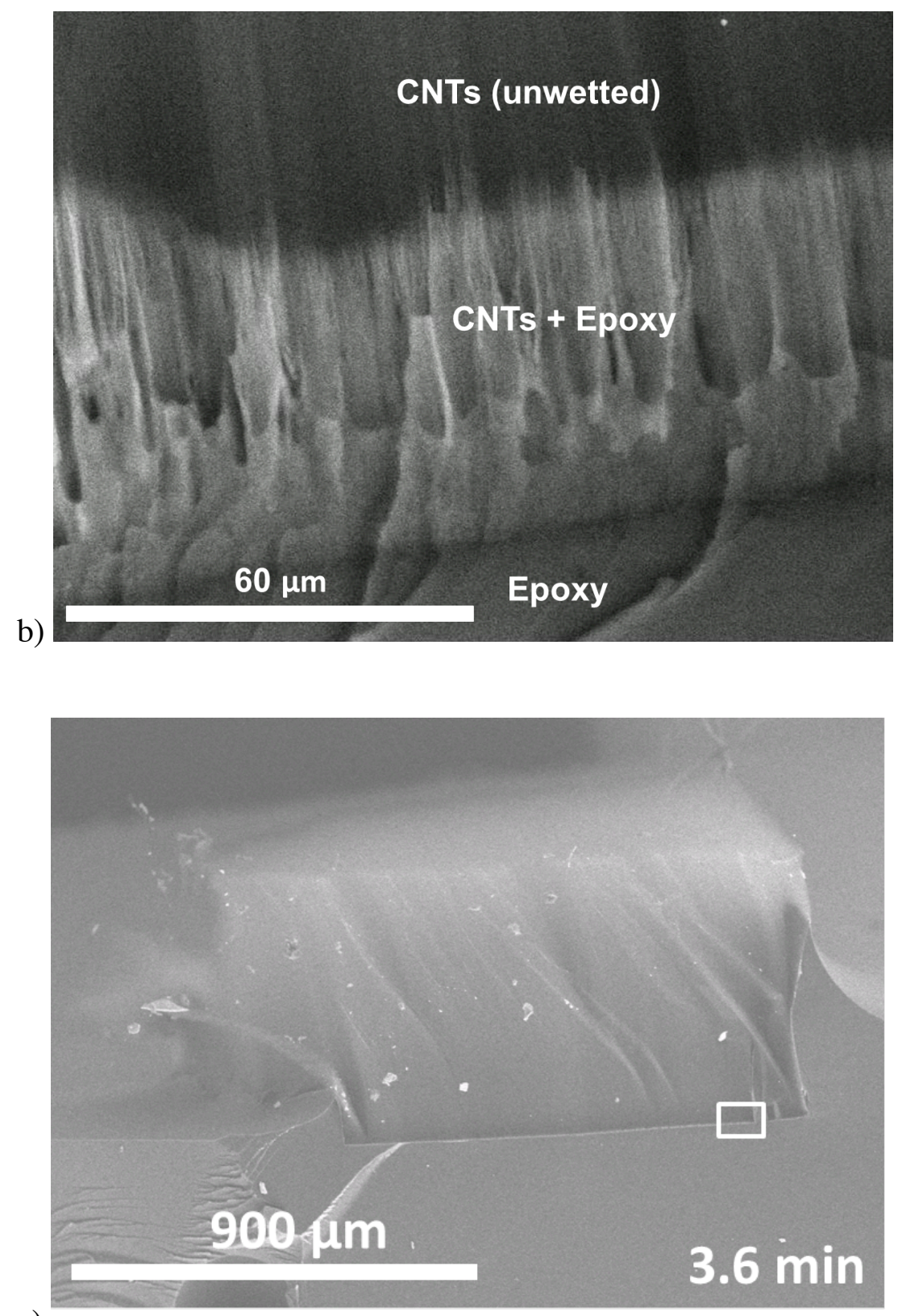

c) 


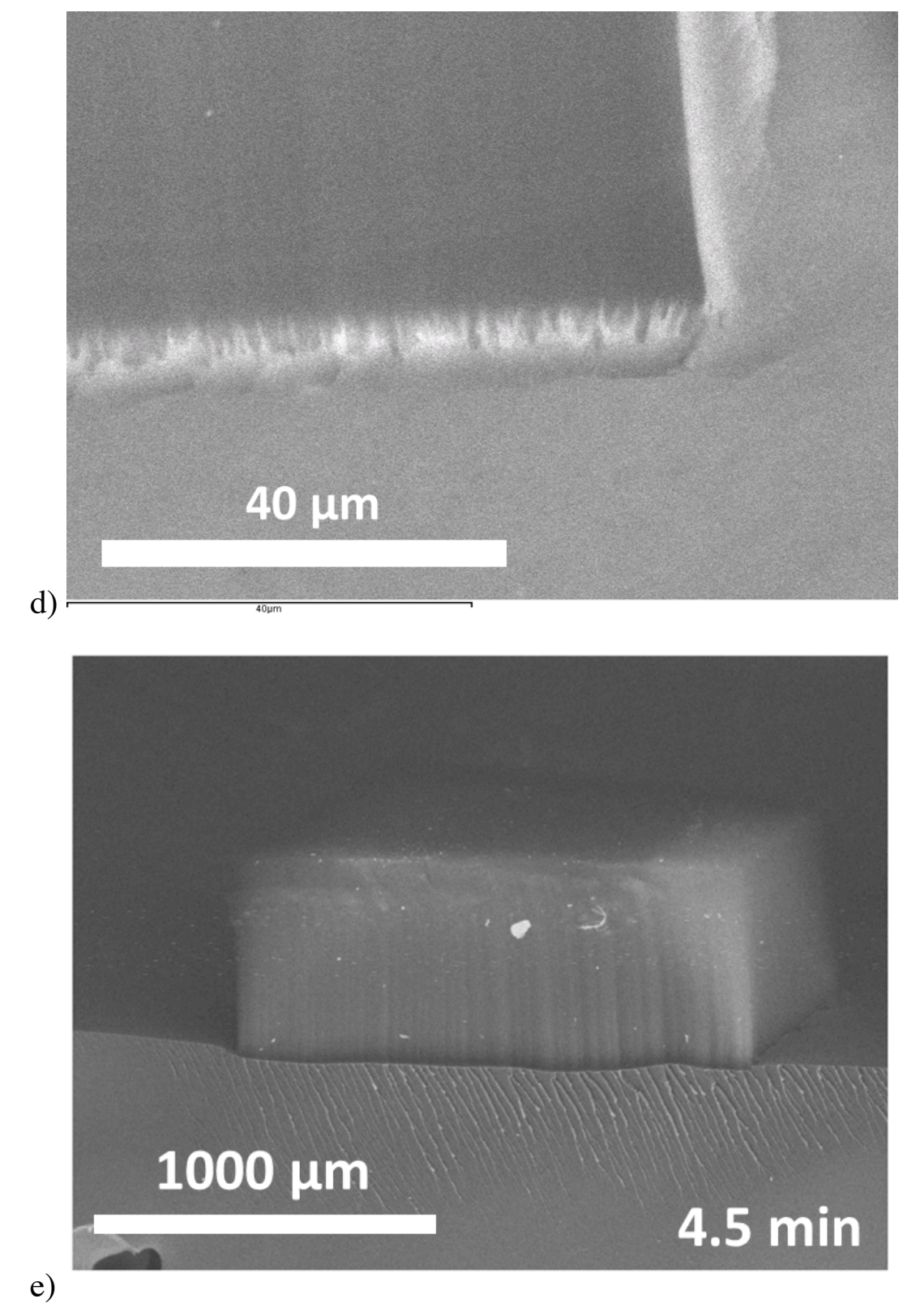




\section{$100 \mu \mathrm{m}$}

f)
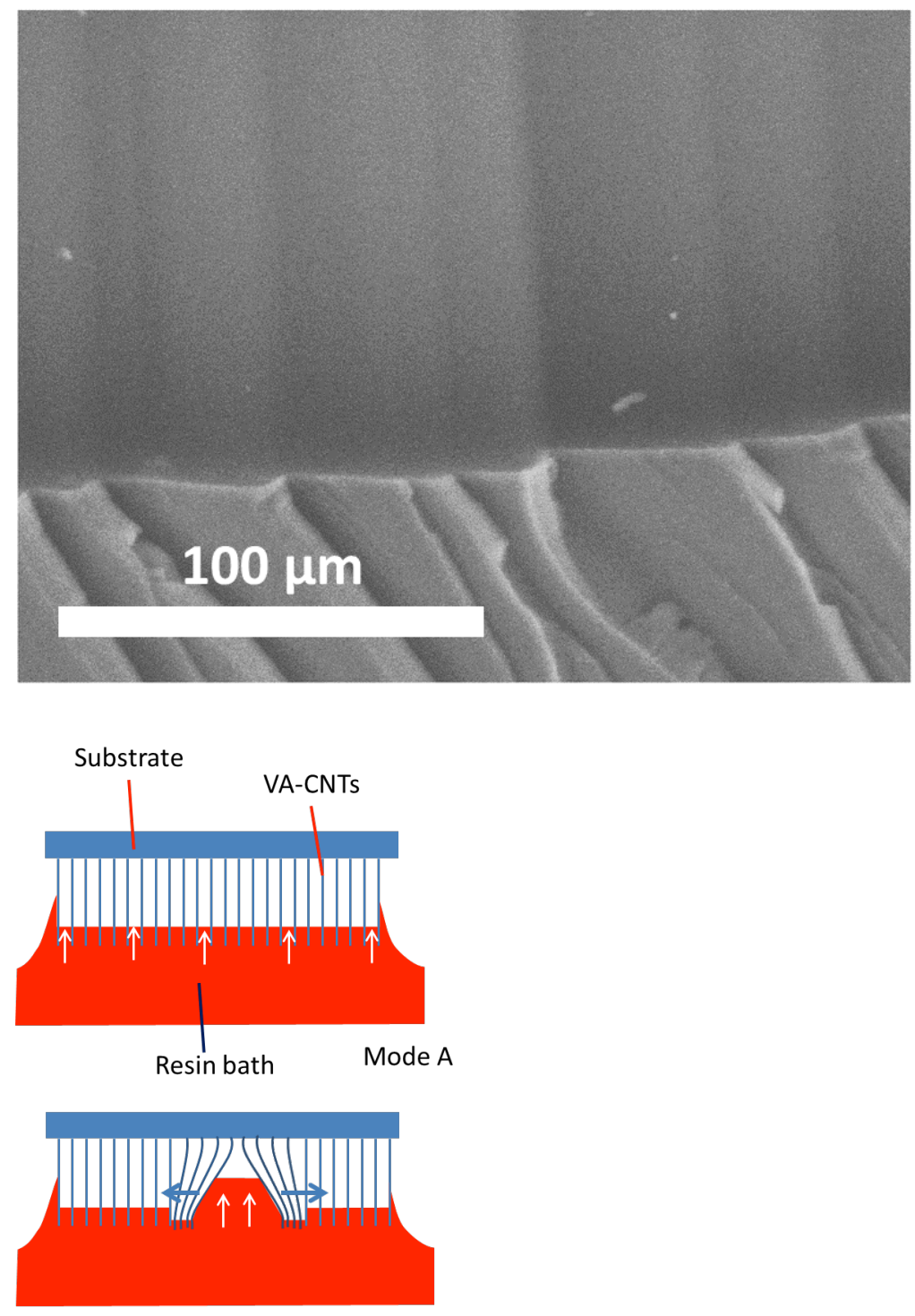

Mode B

Densified VA-CNTs

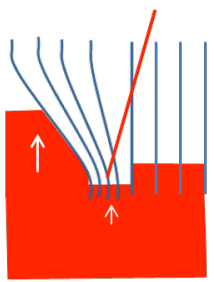

g)

Mode C

Figure 4. "Image gallery" of forests introduced to resin at different times, showing progression from partially-wetted state (a) to unwetted (c). a) Placed in contact after 3.5 minutes, showing pillar-like structures (wetting mode B), as well as a continuous wetted region at the forest base 
(mode A). b) Image of highlighted area in a) with higher magnification, showing interface region of forest at the base (wetting mode A). c) shows a forest wetted principally at the base after 3.6 minutes heating (mode A). d) View of base of forest highlighted by white box in d), showing boundary region at base. e) shows a forest placed in contact after 4 minutes 30 seconds heating, with no wetting effect. f) View of base of forest in $\mathrm{f}$ ), showing no penetration of resin. g) Schematic representation of different modes of wetting. In mode A, the resin wets evenly into the as-grown inter-nanotube gaps. In mode B, "capillary forming" effects create large channels into the forest, resulting in pillar structures and more rapid capillary rise. In addition, it is possible that densification of the nanotube forest around the channel created in mode B slows the penetration of the resin in the densified region (mode C). This may be a cause of the formation of discrete pillars.

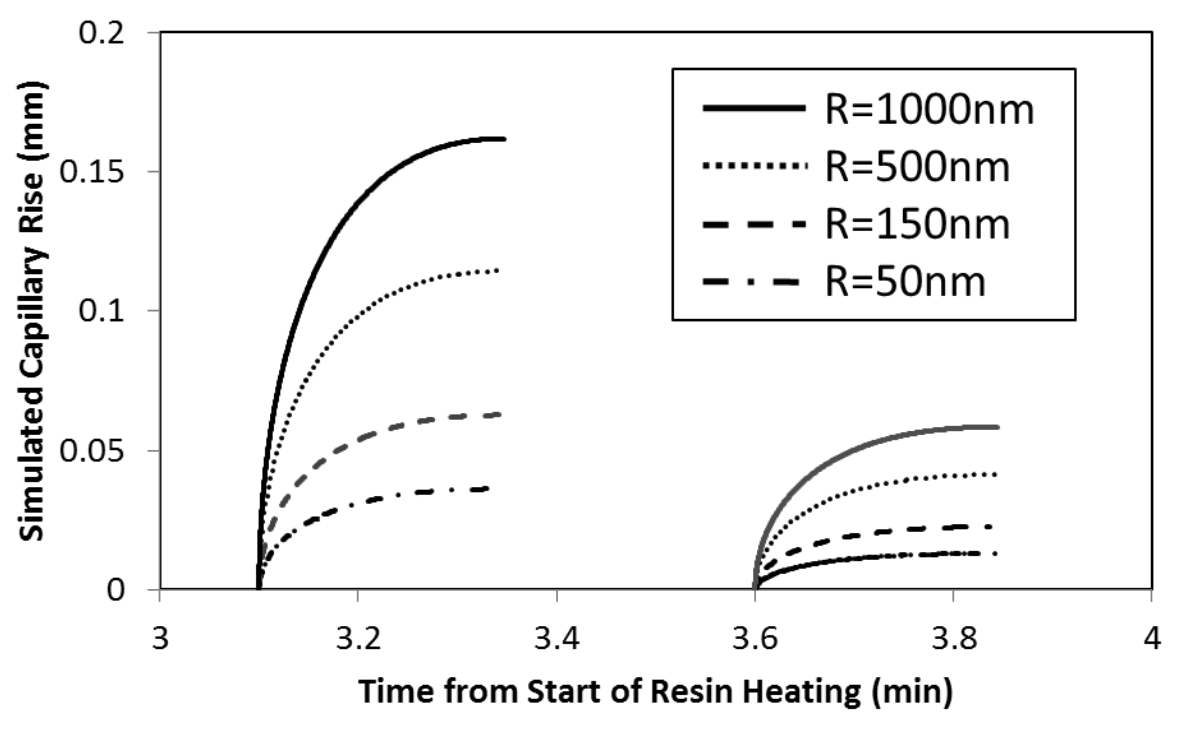

a) 


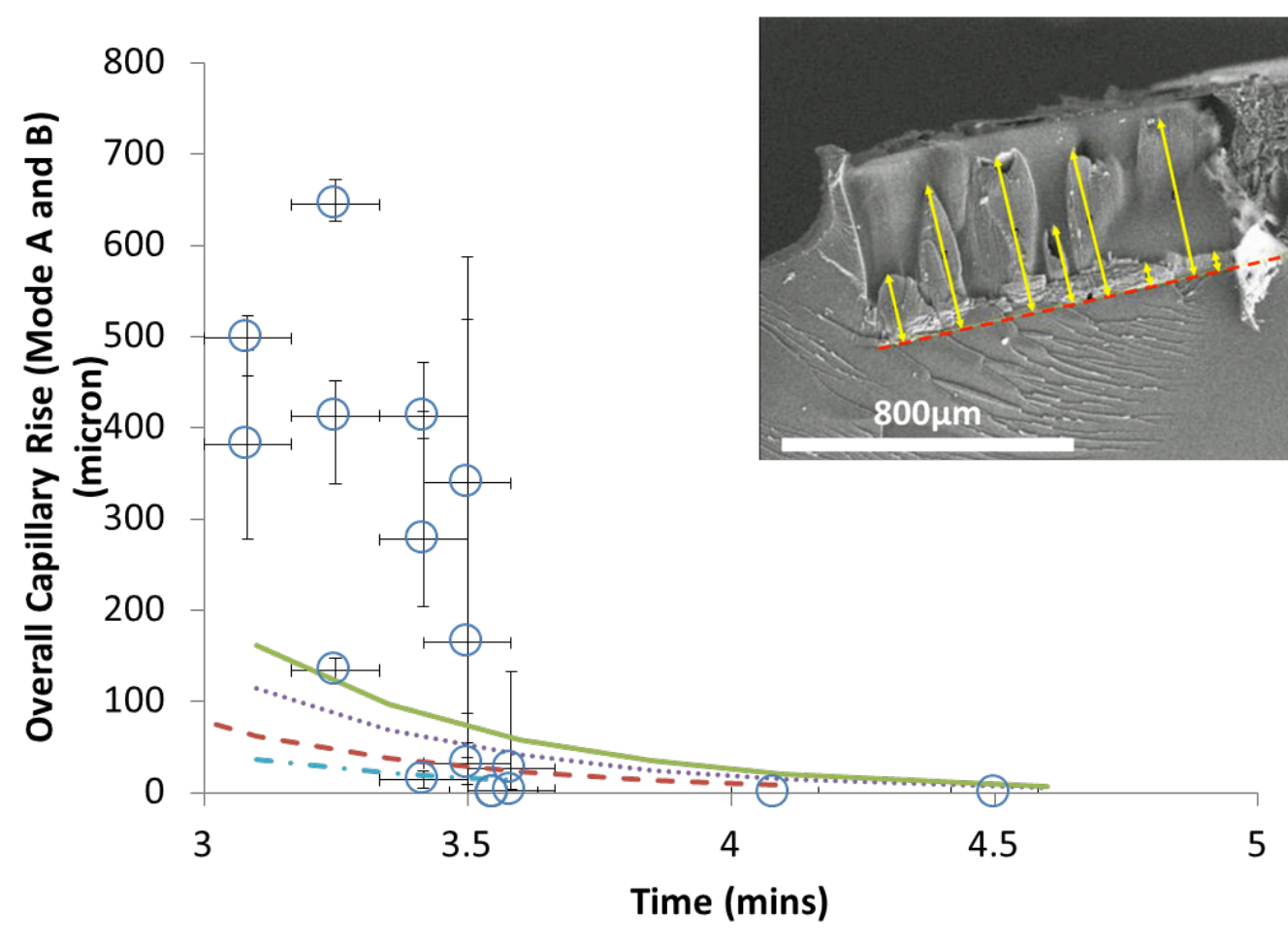

b)

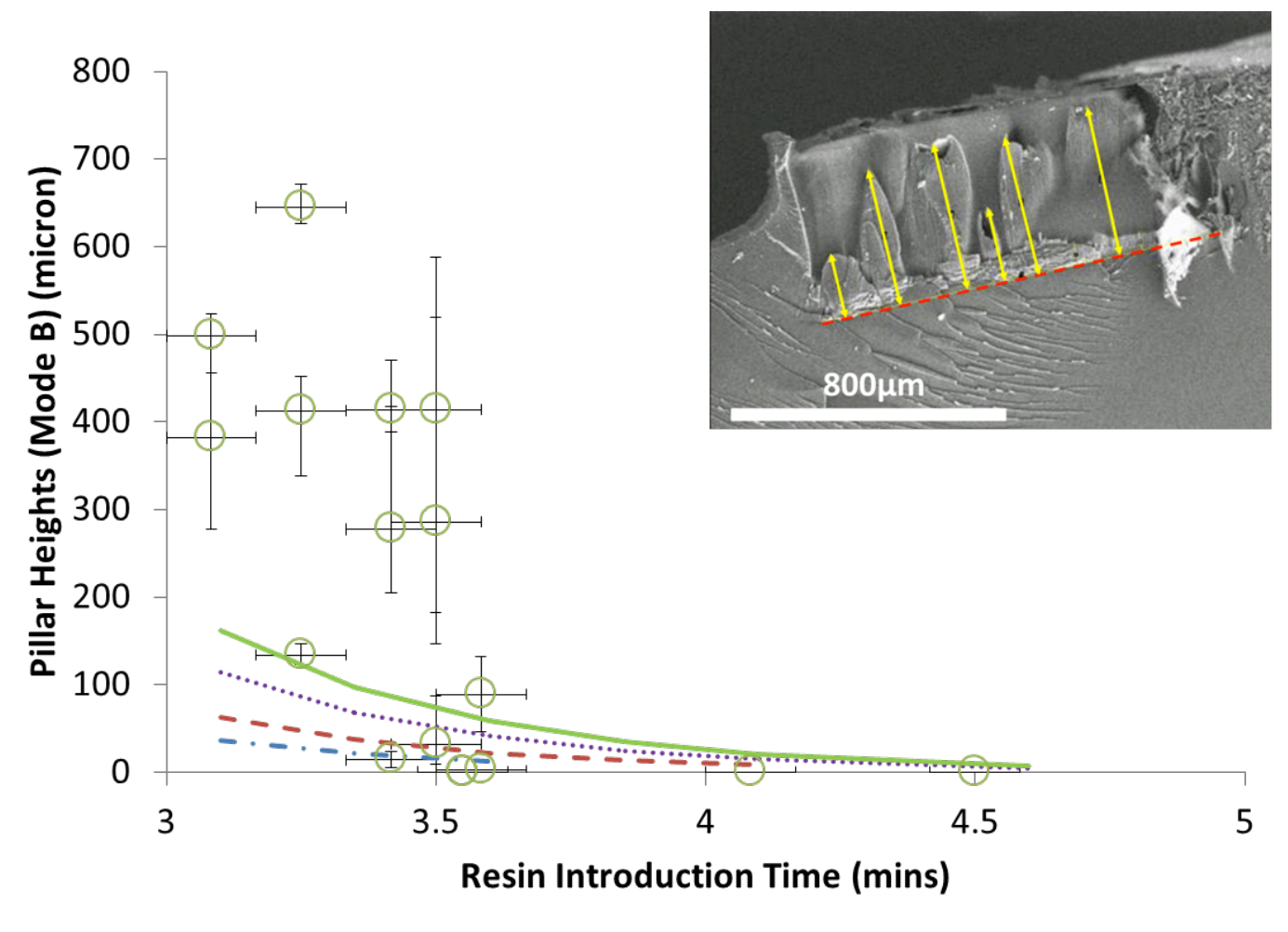



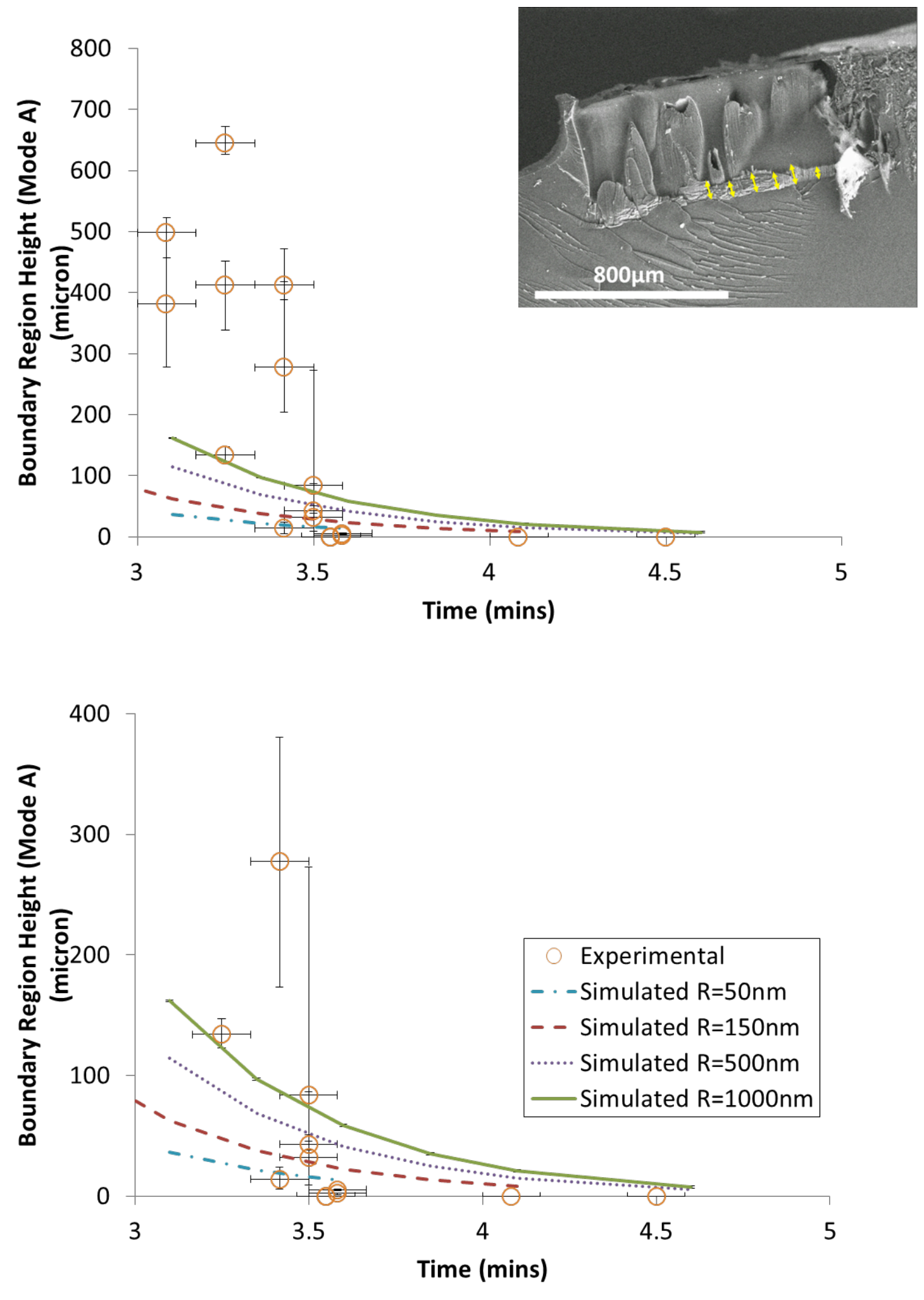
Figure 5. a) Simulated capillary rise based on Implicit Lucas-Washburn model for resin introduced to VA-CNT forest at two different flow initiation times for a range of different capillary radii. b) Rise height of resin within carbon nanotube forests measured from SEM images, compared to simulated results (shown as curves). c) Measurement of pillar heights (wetting mode B). d) Measurement of height of boundary region (wetting mode A). e) Expanded view of plot of data in d) showing only partially wetted forests (excluding those which were fully wetted by resin), compared to the capillary rise predicted by the Implicit Lucas-Washburn model. Note legend for simulated curves is the same for figures $5 \mathrm{~b}$-e. The vertical error bars show maximum and minimum measurements for a given sample, and inset images show examples of measurements on a partially wetted forest.

a)

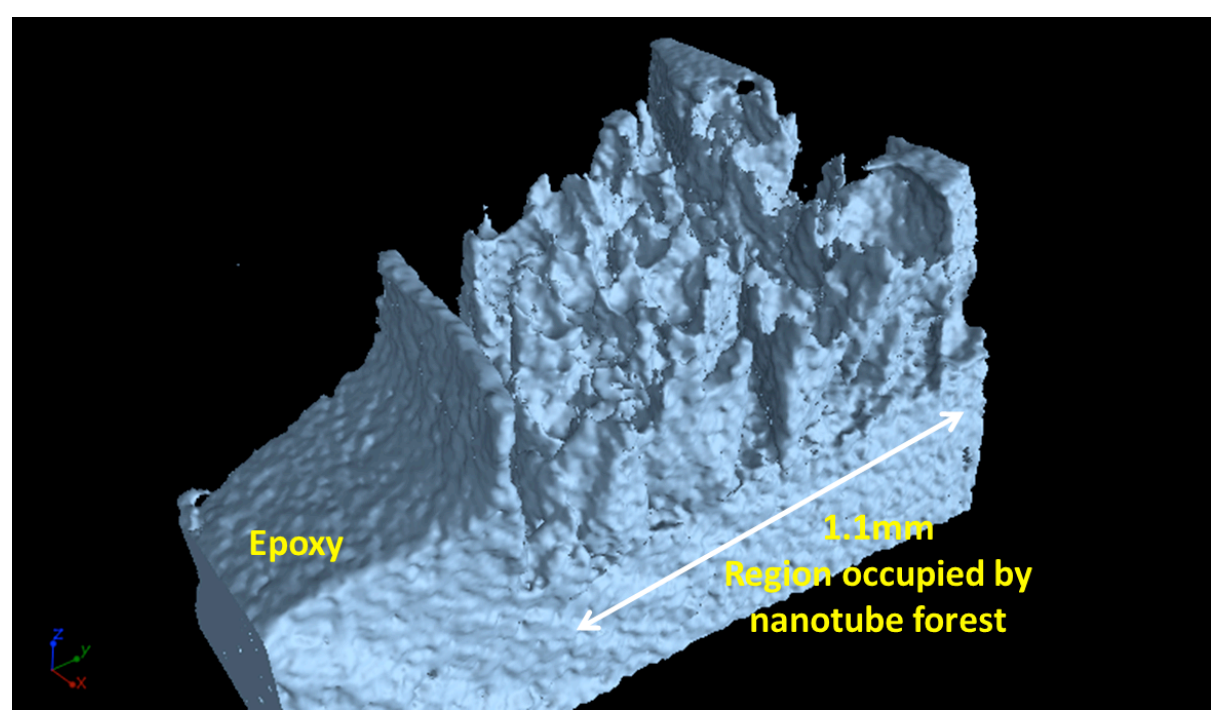


b)

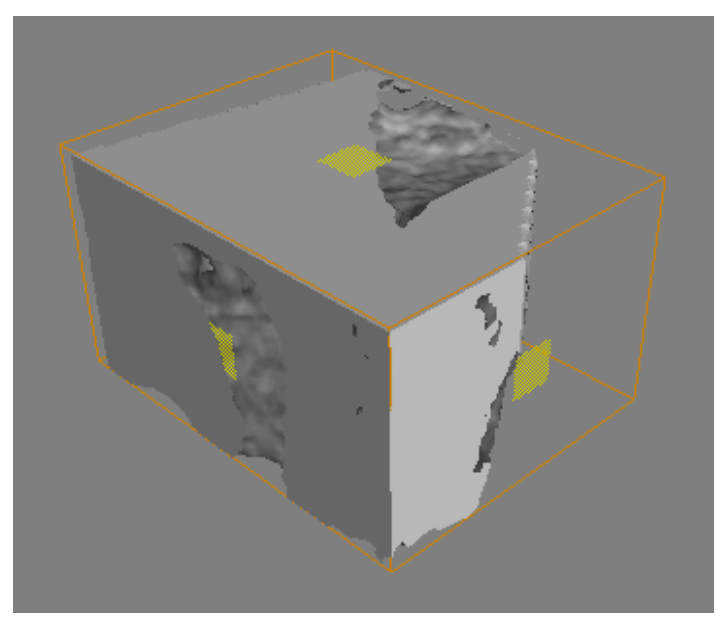

c)

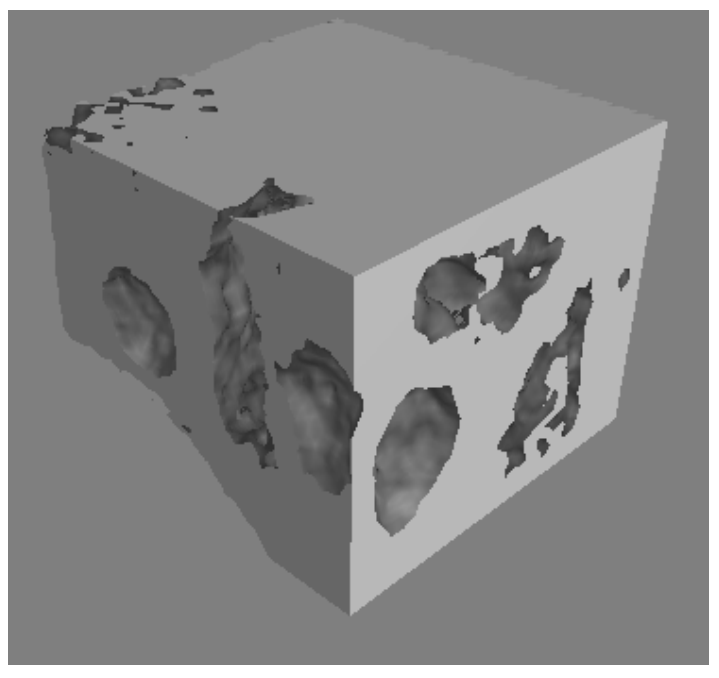

d)

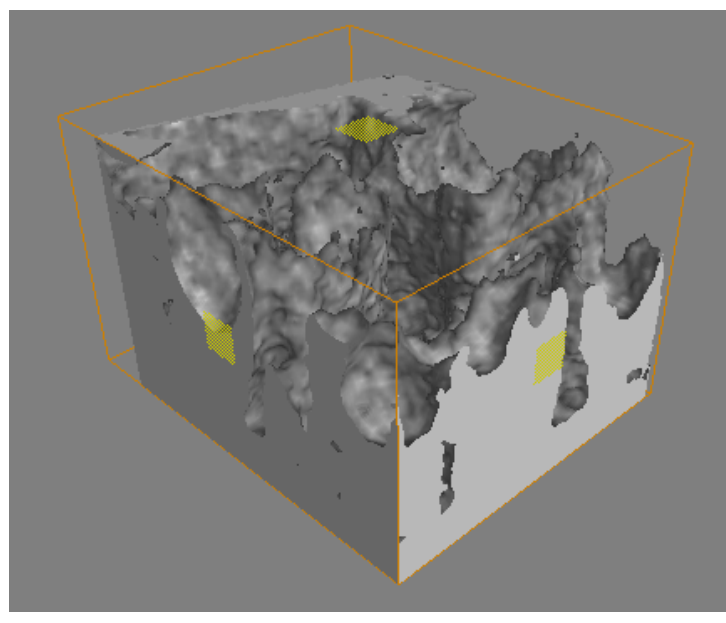



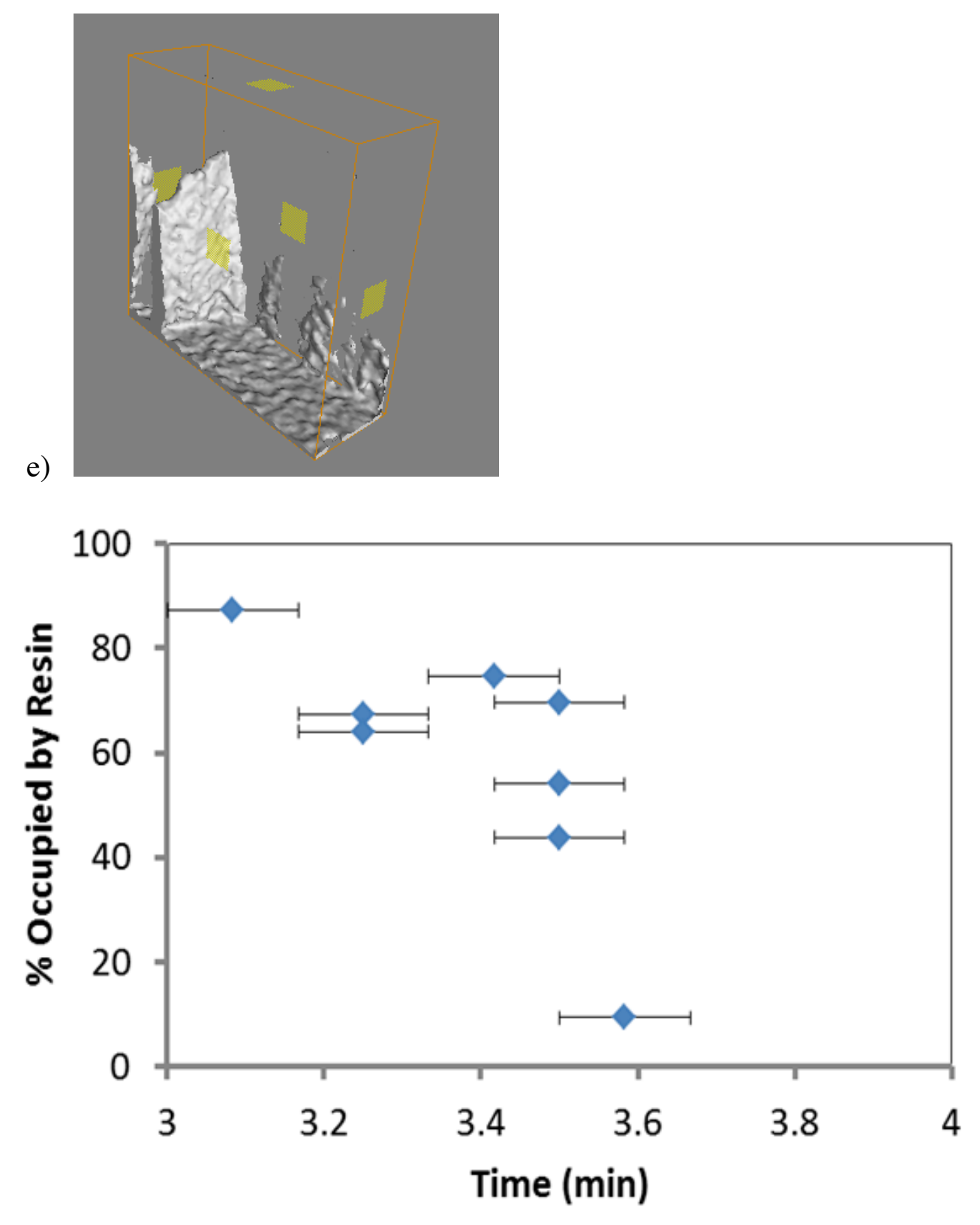

Figure 6. a) $3 \mathrm{D}$ rendered view of CT image of nanotube forest infiltrated by resin, showing "pillar-like" structures formed by the resin, described here as wetting mode B. b-e) Internal structure of resin-infiltrated CNT forests, brought into contact with resin at B: 3.1 mins C: 3.25 mins D: 3.5 mins E: 3.6 mins. f) Calculated percentage of forest volume occupied by epoxy resin. 


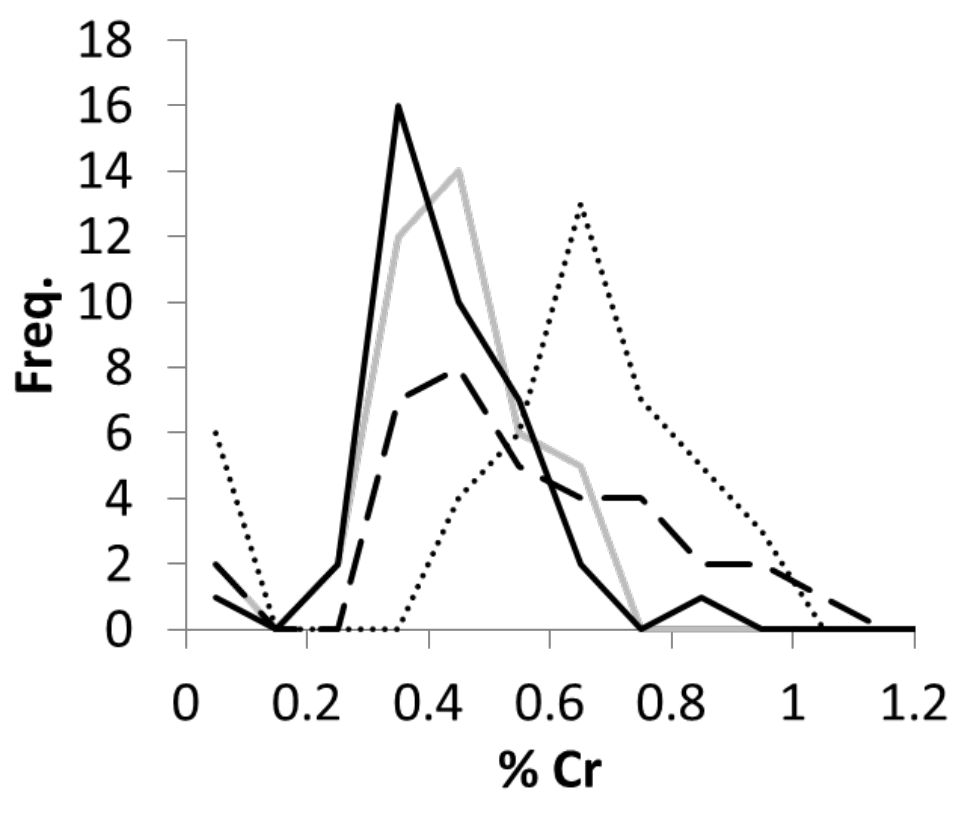

a)

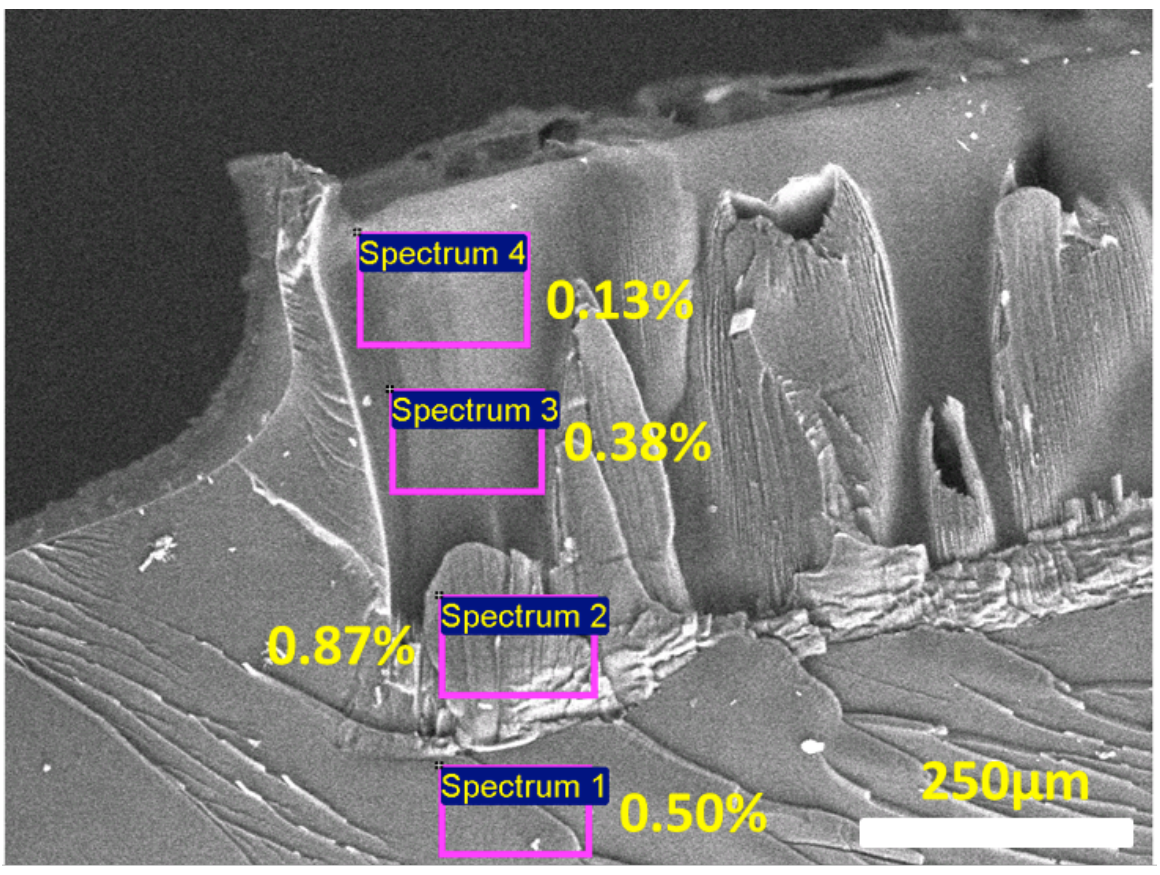




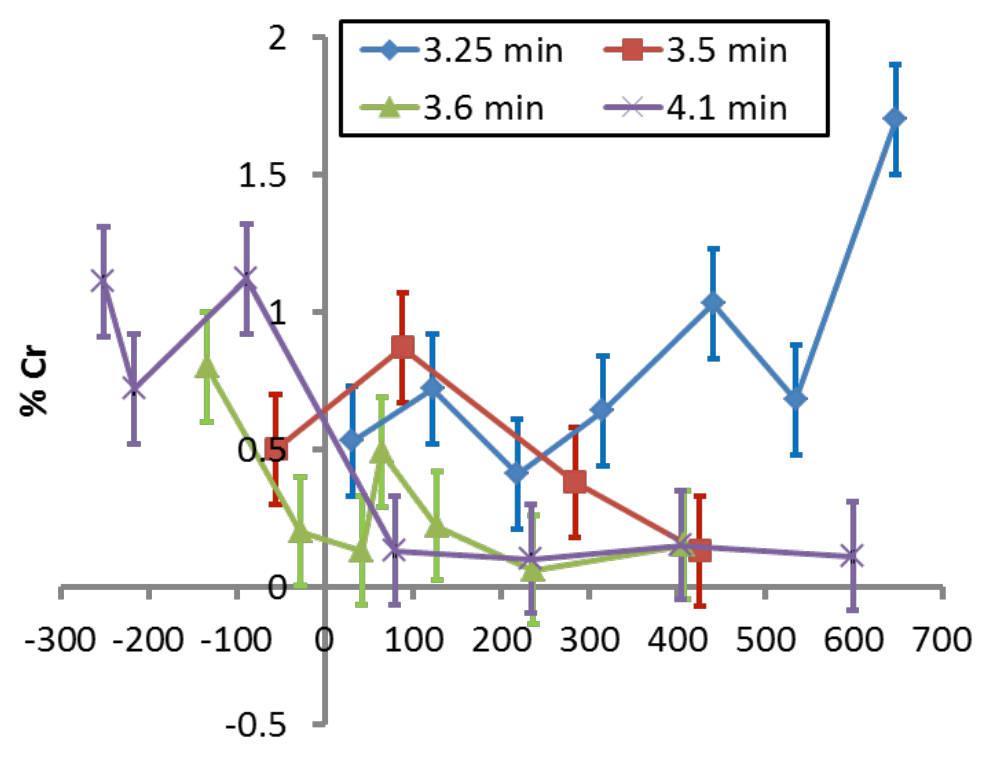

Distance from Forest/Resin Boundary $(\mu \mathrm{m})$

c)

Figure 7. a) Percentages of $\mathrm{Cr}$ by weight measured by EDS, measured on 4 samples of dyed resin (without carbon nanotubes). Different line styles indicate different samples. Means and standard deviations of these distributions are shown in table 1. b) Example of areas examined by EDS, showing percentages of $\mathrm{Cr}$ detected in wetted and unwetted regions. c) Abundance of chromium measured for samples placed in contact with resin over a range of flow initiation times of as a function of distance from the forest/resin interface (distances measured to the centre point of the measured region). Error bars estimated from maximum deviation of $\% \mathrm{Cr}$ measured on resin samples in a).

TABLES

\begin{tabular}{|c|c|c|c|c|}
\hline \multirow[t]{5}{*}{ Sample } & & (t \%) & SD (wt \%) & $N$ \\
\hline & A & 0.69 & 0.14 & 38 \\
\hline & $B$ & 0.58 & 0.20 & 33 \\
\hline & C & 0.44 & 0.12 & 38 \\
\hline & D & 0.45 & 0.10 & 39 \\
\hline
\end{tabular}


Table 1. Mean, standard deviation (SD) and number of measurements on a given sample (N) of percentages of $\mathrm{Cr}$ by weight measured on resin samples (no nanotubes).

\section{AUTHOR INFORMATION}

\section{Corresponding Author}

*Dr James D Beard, Exeter Advanced Technologies, North Park Road, Streatham Campus, University of Exeter EX4 4QF UK

\section{Author Contributions}

The manuscript was written through contributions of all authors. All authors have given approval to the final version of the manuscript.

\section{Funding Sources}

The authors would like to acknowledge Airbus Corp. Ltd. (Airbus Group) and the University of Exeter for funding this research

\section{ACKNOWLEDGMENT}

The authors would like to thank Dr Lesley Wears and Dr Hong Chang of the University of Exeter for their assistance with the SEM/EDS measurements.

\footnotetext{
ABBREVIATIONS

SEM scanning electron microscope, EBL electron beam lithography, EDS energy dispersive xray spectroscopy, SR8 solvent red 8, AM additive manufacturing, PMMA poly(methyl methacrylate), IPA isopropyl alcohol, MIBK 4-methylpentan-2-one, EMK ethyl methyl ketone, CT computed tomography.
}

REFERENCES 
' Iijima, S. Nature, 1991, 354, 56-58.

ii Kim, B.; Chung, H.; Kim, W. Nanotechnology 2012, 23, 155401.

iii Wang, Y.; Yeow, J.T.W.; J Sens. 2009, 2009, 493904

iv Allen, R.J.; Ghita, O.; Farmer, B.; Beard, M.; Evans, K.E.; Compos. Sci. Technol. 2013, 77, $1-7$.

${ }^{\vee}$ Li, X.; Gao, H.; Scrivens, W.A.; Fei, D.; Xu, X.; Sutton, M.A.; Reynolds, A.P.;.and Myrick, M.L. Nanotechnology, 2004, 15, 1416.

vi Jose-Yacaman, M.;Miki-Yoshida, M.; Rendon, L.; Santiesteban, J.G. Appl. Phys. Lett. 1993, 62, 202-204.

vii Hart, A.J.; Slocum, A.H.; J. Phys. Chem. B, 2006, 110, 8250-8257.

${ }_{\text {viii }}$ Meshot, E.R.; Plata, D.L.; Tawfick, S.; Zhang, Y.; Verploegen, E.A.; Hart, A.J.; ACS Nano, 2009, 3, 2477-2486.

${ }^{\text {ix }}$ Hata, K.; Futaba, D.N.; Mizuno, K.; Namai, T.; Yumuru, M., Iijima, S. Science 2004, 306, $1362-1364$.

${ }^{x}$ E.T. Thostenson, Z. Ren, and T.W. Chou. Compos. Sci. Technol., 2001, 61, 1899-1912.

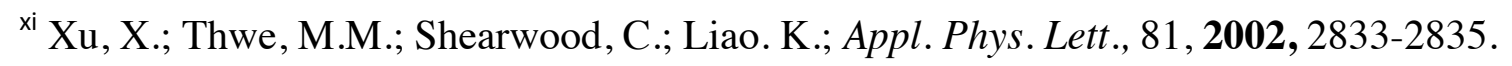


${ }^{\text {xii }}$ Beard, M.A.; Ghita, O.; Farmer, B.; Johns, D; and Evans, K.E.; in Aligned and Dispersed Carbon Nanotube (CNT) Composites: Manufacturing andCharacterization. Proceedings of the 14th European Conference on Composite Materials,

2010 Budapest, Hungary, 7-10 June.

xiii Garcia, E.J.; Hart, A.J.; Wardle, B.L.; Slocum, A.H.; Adv.Mater., 2007, 19, 2151-2156.

${ }^{\text {xiv }}$ Hewitt, C.A.; Kaiser, A.B.; Roth, S.; Craps, M.; Czerw, R.; Carroll. D.L.; Nano Lett., 2012, 12, 1307-1310.

xv Farmer, B.L.; Johns, D.M.; Method and Apparatus for Manufacturing a Composite Material, US Patent Application 8,066,842, Aug 4, 2008

xvi R.J. Allen, O. Ghita, B. Farmer, M. Beard, and K.E. Evans. Wetting Mechanisms of Vertically Aligned Carbon Nanotube (VACNT) Composite Structures in Readiness for Additive Layer Manufacture. In 15th European Conference on Composite Materials, 2012. Venice, Italy. 24-28 June xvii Garcia, E.J.; Hart, A.J.; Wardle, B.L.; Slocum, A.H.; Nanotechnology 2007, 18, 165602. xviii van Laake, L.; Hart, A.J; Slocum, A.H.; Rev. Sci. Instrum. 2007, 78, 083901. xix Meshot, E.R.; Plata, D.L.; Tawfick, S.; Zhang, Y.; Verploegen, E.A.; Hart, A.J.; ACS Nano, 2009, 3, 2477-2486. 
xx Beard, J.D.; Stringer, J.; Ghita, O.R.; Smith, P.J.; ACS Appl. Mater. Interfaces, 2013, 5, 9785-9790.

xxi De Volder, M.; Tawfick, S.H.; Park, S.J.; Copic, D.; Zhao, Z.; Lu, W.; Hart, A.J.; Adv. Mater. 2010, 22, 4384-4389. 